\title{
From Digital Community Engagement to Smoking Cessation: Insights from the Reddit r/StopSmoking Thread
}

\author{
Alessio De Santo \\ University of Neuchâtel \\ alessio.desanto@unine.ch
}

\author{
Arielle Moro \\ University of Neuchâtel \\ arielle.moro@unine.ch
}

\author{
Bruno Kocher \\ University of Neuchâtel \\ bruno.kocher@unine.ch
}

\author{
Adrian Holzer \\ University of Neuchâtel \\ adrian.holzer@unine.ch
}

\begin{abstract}
Despite decades of prevention, tobacco addiction is still a widespread health concern responsible for around 8 million deaths per year. Existing digital solutions such as social media are becoming increasingly popular and represent a novel approach for people to find community support. However, little is known about how they affect smoking behavior. This paper tackles this issue by investigating attitudes, motivations and behaviors of 169 users of one such digital community, namely the Reddit $r$ /StopSmoking thread. We present a model based on the transtheoretical model as well as the uses and gratification approach that investigates the support of digital communities in the smoking cessation process. Our findings suggest that engagement in online smoking cessation communities has a positive link to smokers' behavior in their process of change. Providing help, seeking help, seeking information, seeking status and seeking entertainment being identified as motivational factors to engage in such online communities.
\end{abstract}

\section{Introduction}

According to the World Health Organization (WHO), tobacco use is the starting point for many non-communicable diseases (NCDs) and is responsible for over 8 million deaths annually [1]. Most smokers, who are aware of the dangers of tobacco, would like to quit but need help to do so [2]. Simple behavioral change interventions can considerably reduce the premature deaths of tobacco users [2]. Past research has investigated which interventions can effectively reduce the premature deaths of tobacco users. According to primary care guidelines, brief advice, behavioral support, pharmacotherapy and abstinence evaluation are the only four interventions providing strong evidence of efficacy [3]. However, these evidence-based interventions are still largely underused [4]. For instance, face-to-face counseling, which is the most effective way to help smokers to quit [5], has only low participation rates [6] and is also not affordable globally [7]. Reaching smokers with this evidence of efficacy interventions will require novel approaches to enhance the effectiveness of existing cessation interventions, and to increase their adoption.

To support individuals in adopting healthier behaviors, digital artifacts are increasingly available $[8,9,10]$. Social networks [11], social support [12], and social integration [13] appear to play important roles in smoking behavior and can potentially provide helpful complementary support for smoking cessation [5]. Among available digital resources, social media are becoming increasingly popular for people in search of health information and support [14, 15]. On these platforms, the digital community, i.e., the group of people interacting on the platform, can potentially provide $24 / 7$ behavioral support and brief advice through messaging. However, evidence on how digital communities can support tobacco cessation are still limited [16, 17].

This paper addresses this issue by investigating how such digital communities provide support for smokers who are attempting to quit. This research provides an understanding of motivation to participate in digital smoking cessation communities and its behavioral impact on individuals' online engagement and offline smoking cessation process of change. More specifically, we contribute to the literature by providing a novel research model (Section 3) based on the transtheoretical model as well as the uses and gratification approach. Our model aims to predict online engagement and eventually the progress in smokers' behavioral process of change towards becoming an ex-smoker. This research also aims at understanding how online activities support smokers' process of change. We instantiate this model (Section 4) using insights from users of a real social media community ( $\mathrm{r} /$ StopSmoking on Reddit) which includes more than $100 \mathrm{k}$ members, $115 \mathrm{k}$ posts and 750k comments. Finally, in Sections 5 and 6, we discuss results and finally draw a conclusion. 


\section{Literature review and hypotheses}

Here, we review the relevant literature for our work and present five hypotheses that we aim to evaluate.

\subsection{Towards smoking cessation}

The director of the $\mathrm{O} 2$ Foundation, a regional anti-tobacco agency, explains that "on average it takes around seven attempts before someone manages to quit for good". According to their experience, quitting for a smoker, is more of a process than a single act following a decision. A useful theoretical model, matching this idea of process, is the transtheoretical model (TTM) [18]. This model based on stages, differs from many other behavioral theories based on so-called continuum models. According to continuum models, interventions could be applied in any order, or even simultaneously, and do not include any notion of progression [19]. Stage models imply that different interventions are appropriate at different stages of health behavior change [19], making for instance TTM a frequently used model for smoking cessation intervention [20]. Even if stage models have also been criticized [21, 22], arguing that the notion of stages might be flawed or circular, in that the stages are not genuinely qualitative, they still have this notion of progression, which goes beyond the sole variation of intention including the action and post-action spectrum. TTM has become one of the most popular stage models [19] and despite the controverted boundaries of the stages or the circularity that multiple stop-smoking attempts could represent, independent variables provided by the processes of change, can provide a sentiment concerning the smoker's progression.

TTM hypothesizes that this change occurs in six distinct steps or stages, also called stages of change:

- Stage 1 , precontemplation, i.e. no intention to take action within the next six months;

- Stage 2, contemplation, i.e. intention to take action within the next six months;

- Stage 3, preparation, i.e. intention to take action within the next 30 days with some behavioral steps in this direction already taken;

- Stage 4, action, i.e. changed overt behavior for less than six months;

- Stage 5, maintenance, i.e. changed overt behavior for more than six months;

- Stage 6, termination, no temptation to relapse and $100 \%$ confidence.
TTM further suggests a set of 10 processes mediating the progress between stages (see Table 1). Empirical integration [23] suggests that, in early stages, smokers rely on cognitive, affective and evaluative processes to progress through the stages. In later stages, smokers work more on commitments, conditioning, contingencies, environmental controls and support for progressing toward maintenance or termination.

\begin{tabular}{|c|c|}
\hline Process of Change & Description \\
\hline $\begin{array}{l}\text { Consciousness } \\
\text { raising } \\
(\text { Stage } 1 \rightarrow 2)\end{array}$ & $\begin{array}{l}\text { Increasing awareness via information, } \\
\text { education and personal feedback about } \\
\text { the healthy behavior }\end{array}$ \\
\hline $\begin{array}{l}\text { Dramatic relief } \\
(\text { Stage } 1 \rightarrow 2)\end{array}$ & $\begin{array}{l}\text { Feeling fear, anxiety or worry because of } \\
\text { the unhealthy behavior, or feeling } \\
\text { inspiration and hope when they hear } \\
\text { about how people are able to change to } \\
\text { healthy behaviors }\end{array}$ \\
\hline $\begin{array}{l}\text { Environmental } \\
\text { reevaluation } \\
(\text { Stage } 1 \rightarrow 2 \text { ) }\end{array}$ & $\begin{array}{l}\text { Realizing the negative impact of the } \\
\text { unhealthy behavior or the positive impact } \\
\text { of the healthy behavior on one's proximal } \\
\text { social and/or physical environment }\end{array}$ \\
\hline $\begin{array}{l}\text { Self-reevaluation } \\
(\text { Stage } 2 \rightarrow 3)\end{array}$ & $\begin{array}{l}\text { Realizing that the behavior change is an } \\
\text { important part of one's identity as a } \\
\text { person }\end{array}$ \\
\hline $\begin{array}{l}\text { Self-liberation } \\
(\text { Stage } 4 \rightarrow 5)\end{array}$ & Making a firm commitment to change \\
\hline $\begin{array}{l}\text { Helping } \\
\text { relationships } \\
(\text { Stage } 5 \rightarrow 6 \text { ) }\end{array}$ & $\begin{array}{l}\text { Seeking and using social support for the } \\
\text { healthy behavior change }\end{array}$ \\
\hline $\begin{array}{l}\text { Counterconditioning } \\
\text { (Stage } 5 \rightarrow 6 \text { ) }\end{array}$ & $\begin{array}{l}\text { Substitution of healthier alternative } \\
\text { behavior and cognition for the unhealthy } \\
\text { behavior }\end{array}$ \\
\hline $\begin{array}{l}\text { Reinforcement } \\
\text { management } \\
(\text { Stage } 5 \rightarrow 6)\end{array}$ & $\begin{array}{l}\text { Increasing the rewards for the positive } \\
\text { behavior change and decreasing the } \\
\text { rewards of the unhealthy behavior }\end{array}$ \\
\hline $\begin{array}{l}\text { Stimulus control } \\
(\text { Stage } 5 \rightarrow 6)\end{array}$ & $\begin{array}{l}\text { Removing reminders or cues to engage in } \\
\text { the unhealthy behavior and adding cues } \\
\text { or reminders to engage in the healthy } \\
\text { behavior }\end{array}$ \\
\hline $\begin{array}{l}\text { Social liberation } \\
\text { (no specific Stage) }\end{array}$ & $\begin{array}{l}\text { Realizing that the social norms are } \\
\text { changing in the direction of supporting } \\
\text { the healthy behavior change }\end{array}$ \\
\hline
\end{tabular}

Table 1. Processes of change that mediate progression between the stages of change

\subsection{Evidence-based interventions}

Four interventions for smoking cessation have been found to be supported by evidence [3]: (1) pharmacotherapy, (2) brief advice, (3) behavioral support and (4) abstinence evaluation. Examples of pharmacotherapy include nicotine replacement therapy and the use of bupropion or varenicline to assist patients with nicotine withdrawal. A brief advice is $5-10$ minutes of advice to encourage smokers to improve their health by quitting their smoking habit, primarily by triggering a cessation attempt. Behavioral support includes: self-help material, peer group meetings and health professional counseling. Self-help information can support patients without outside help. When self-help is personalized, it is 
even more effective [24]. With peer group meetings, smokers who attempt to quit meet regularly and provide each other with support and encouragement. Health professional counseling generally consists of one-on-one face-to-face appointments between a medical professional and a smoker. Enhancing the motivation to stop smoking through behavioral support has been identified as an important aspect of the overall treatment for tobacco addiction [24]. Finally, abstinence evaluation is the confirmation of abstinence through either self reporting or objective measures such as biochemical markers or clinical tests.

\subsection{Digital communities for smoking cessation}

Several studies have analyzed online smoking cessation communities $[16,25,26,27]$. Some studies investigated the effectiveness of health behavior interventions on online social communities, finding none, very modest or ambivalent evidence of efficacy $[25,27]$. Others used observational rather than interventional approaches to understand peer-generated content and interactions [28, 26]. From this perspective, emerging results suggest that peer support is helpful in avoiding smokers relapsing [16]. Researchers argue that digital communities can be perceived as a "safe space" for smokers to talk about day-to-day challenges, cravings or relapses [26]. Furthermore, the relative anonymity of the Internet can facilitate discussion and mutual support [26]. A wide variety of peers can be available at any time to provide help and support through various activities, such as sharing information, sympathizing, cheering, coaching or celebrating. Some of these peers, potentially further along the line, can be considered as expert patients. They can provide firsthand experience about how to cope, what to expect and how things feel [27].

Digital interventions can be seen as potentially supporting several evidence-based interventions. For instance, digital communities have been found to contribute to significant long-term positive health outcomes through their information-providing role (self-help material) [29, 30]. However, it is not yet clear how engagement in such communities is linked to the actual process of behavior change. Digital interventions can also be seen as potentially supportive peer group meetings. Unfortunately, research results are not yet conclusive [31]. A better differentiation of social support concepts and causal pathways is awaiting further investigations to demonstrate the effective value of social relationships in improving smokers' likelihood of cessation [12].
One of the important factors to assess the impact of online communities is participant (i.e. user) engagement. User engagement in a digital community can be defined as the different activities users perform in an online community. These activities can be divided into active contributing activities (e.g. posting messages, reacting to a comment, sharing a video) and passive consuming activities (e.g. viewing content, visiting a page) $[32,33]$. Based on these definitions, we make the following hypotheses:

H1: Overall engagement in digital smoking cessation communities is positively linked to the process of change.

H1a: Active engagement in digital smoking cessation communities is positively linked to the process of change.

H1b: Passive engagement in digital smoking cessation communities is positively linked to the process of change.

\subsection{Motivation for digital community engagement}

To understand the motivational factors influencing engagement in digital communities, the uses and gratifications theory is widely relied upon [34], even though it was originally developed to examine how and why individuals use and adopt mass media in their daily lives [35]. As depicted in Table 2, this theory describes four motivational factors to predict engagement in digital communities [33, 34, 36]: information-seeking, socialization, status-seeking and entertainment.

The uses and gratifications theory already stands as a valid means of examining the motivations and gratifications sought and obtained by users of online communities [33, 34, 36]. However, recent literature is still calling for contributions to further expand this approach by, for instance, examining new needs and motivations [33]. To expand this model, it is considered that one possibility is to integrate recent findings about behavior change [33], in this case the evidence that giving advice is even more useful than receiving advice [41, 42]. Smoking cessation being a process in which one is not immune from relapsing, providing support may have a twofold positive impact, for people receiving the support but also people providing it. To reflect the dual aspect of seeking advice and providing advice discussed above, we suggest expanding the socialization factor into two relevant subfactors: (1) Providing help and (2) Seeking help. Providing help is measuring users' motivation to help others in their smoking cessation process, which would represent "expert" users who are further ahead 


\begin{tabular}{|c|c|}
\hline $\begin{array}{l}\text { Motivational } \\
\text { factor }\end{array}$ & Description \\
\hline $\begin{array}{l}\text { Information } \\
\text { seeking }\end{array}$ & $\begin{array}{l}\text { Seeking and obtaining credible, useful } \\
\text { information is one of the primary motivations } \\
\text { for Internet use [37]. Information seeking has } \\
\text { been positively associated with social networks } \\
\text { participation in past studies [34, 38]. Online } \\
\text { communities represent a wealth of information } \\
\text { for smokers providing self-help material. }\end{array}$ \\
\hline Socialization & $\begin{array}{l}\text { Previous studies have found socialization as } \\
\text { strong motivations among users }[38,36,33] \text {. } \\
\text { Building and maintaining social contacts are } \\
\text { among the most prevalent reasons for } \\
\text { participation in online communities }[36,33] \text {. } \\
\text { Smokers may also use such channels to share } \\
\text { about their quitting journey and to exchange } \\
\text { peer support. }\end{array}$ \\
\hline Status-seeking & $\begin{array}{l}\text { Improving one's social status has been shown to } \\
\text { be a strong motivating factor from a uses and } \\
\text { gratifications perspective in studies of social } \\
\text { network usage }[34,33] \text {. }\end{array}$ \\
\hline Entertainment & $\begin{array}{l}\text { The need for pleasurable, emotional and } \\
\text { aesthetic experiences has been found to be a } \\
\text { strong motivation factor in Internet and social } \\
\text { network usage [36, 33]. Studies have indicated } \\
\text { that reading and sharing content may also meet } \\
\text { entertainment needs for users [39]. } \\
\text { Entertainment can also be perceived as a good } \\
\text { way to get smokers' minds off cigarettes [40] }\end{array}$ \\
\hline
\end{tabular}

Table 2. Motivational factors to participate in online smoking cessation communities

on the withdrawal journey and are willing to provide firsthand experience and support [27]. Help-seeking aims to measure a user's motivation to engage in online communities to exchange with others in order to receive help. These observations lead to the following hypotheses:

H2: Uses and gratification motivational factors will be positively linked to engagement in online smoking cessation communities.

H3: Seeking help and providing help, are important motivational factors to participate in online smoking cessation communities.

\section{Research method}

This study focuses on a particular digital smoking cessation community, the popular Reddit social media platform, and in particular its $\mathrm{r} /$ StopSmoking subreddit, which is one of the largest and most active community dedicated to smoking cessation (more than 100k users, $115 \mathrm{k}$ posts and $750 \mathrm{k}$ comments).

A subreddit can be seen as a shared forum where users can post messages, reply with comments and vote messages up or down. Each Reddit user, also known as a redditor, can join $\mathrm{r} /$ StopSmoking and ask or give advice, share stories or encourage someone who is trying to quit.

The following sections provide a description of the survey, a presentation of the model and method used to analyze the data, and a description of the participants, through key data.

\subsection{Survey}

This study employed a survey designed to assess individuals' motivation to participate in r/StopSmoking, their level of engagement and the perceived influence of the community on their process of behavior change. The survey was validated by the University of Neuchâtel ethics committee, was published for the first time in this research and asked for informed consent of participants. Respondents were anonymous and could stop at any time. The survey was composed of five distinct sections.

The first section included descriptive facts such as the date when the first cigarette was smoked or the number of cessation attempts.

The second section focused on engagement in r/StopSmoking. Engagement was measured by asking participants how frequently performed the following types of activities: visiting, reading, posting, commenting and voting. The first two activities are considered passive engagement, whereas the latter three are instances of active engagement. These activities were measured using a five-point scale: "never", "almost never", "occasionally/sometimes", "almost every time" and "every time". Frequency of visiting was measured through a question asking for the average monthly number of visits with possible answers ranging from "less than 1" to "30 or more".

The third section of the survey measured the motivation to participate in $\mathrm{r} / \mathrm{StopSmoking}$. Motivation to participate was measured through four factors according to the uses and gratification approach: information-seeking, status-seeking, socialization and entertainment. The information-seeking, status-seeking and entertainment factors were directly taken and adapted from prior instruments employed in uses and gratifications research $[33,34,36]$. The socialization factor was also adapted from previous research, but the questions were linked to the novel factors provide help or seek help according to the direction of the interaction. For instance, one of the questions used for the provide help factor asked whether the respondent participated in $\mathrm{r} /$ StopSmoking subreddit to help others. In contrast, one of the questions used for seek help factor asked if the respondent participated in $\mathrm{r} / \mathrm{StopSmoking}$ subreddit to gain peer support from others. All factors were measured with multiple questions, using five-point Likert scales.

The fourth section of the survey focused the behavior change process. The process of change was measured through the individual's accomplishment of the various processes mediating the progression between the stages of change of the TTM process of change (see Table 1). For instance, to measure whether $\mathrm{r} / \mathrm{StopSmoking}$ 


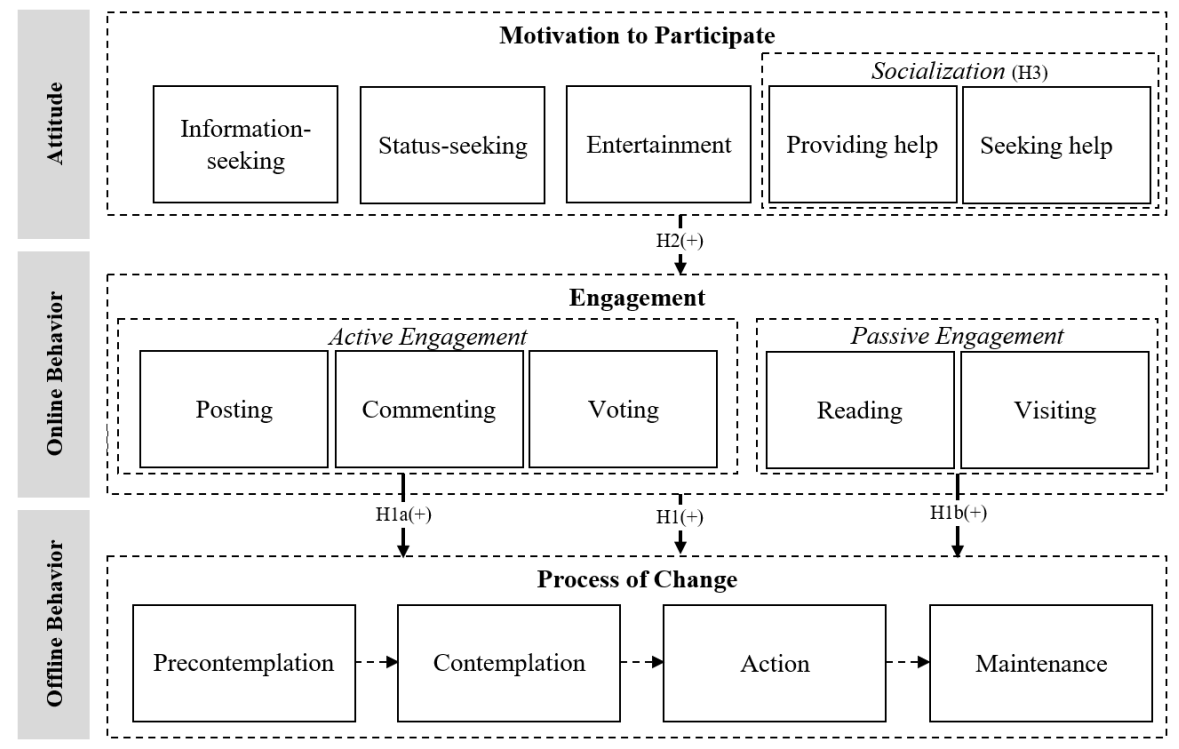

Figure 1. Research model

helped people to move from precontemplation to contemplation we inquired if $\mathrm{r} / \mathrm{StopSmoking}$ allowed users to accomplish the corresponding processes of change: consciousness raising, dramatic relief and environmental reevaluation. For instance, consciousness raising accomplishment was measured by asking participants if the digital community allowed them to increase their awareness via information, education and personal feedback about smoking cessation (see Table 1). For each process, the accomplishment was measured with the same question structure, and individuals could then answer through a five-point Likert scale. Each stage of change was finally measured as a formative construct - based on the various processes that would allow them to progress beyond it - giving indicators measured through five-point Likert scales. As there are no clear processes allowing people to move on from the preparation and termination stages, they were not included in our model. The fifth and final section focused on optional demographics (age, gender) not exploited in this study.

\subsection{Model and analysis}

Partial least squares (PLS), a variance-based structural equation modeling (SEM) analysis technique, was used for assessing our model and our hypotheses. PLS is an increasingly popular technique in IS research to analyze explanation and prediction of IS phenomena [43, 44, 45]. Central to PLS is the path model, a diagram that displays the hypotheses and variable relationships to be estimated in an
SEM analysis [46]. The construction of our path model (Figure 1) includes three main dimensions: (1) attitude, referring to motivation to participate in the digital community, (2) online behavior, referring to engagement in the digital community, and (3) offline behavior, referring to the process of behavior change.

\subsection{Participants}

Users of the r/StopSmoking subreddit were invited to participate in the survey through links posted directly to the site. The survey was completed on a voluntary basis and no compensation was given to respondents. A total of 173 responses were collected from 11 February to 11 April 2020. To maintain the visibility of the invitation among other posts, invitations to participate in the survey were randomly re-posted 18 times throughout the data collection period. After preliminary analyses and data preparation to remove outliers, 169 participants were included in the analysis (83 females and 1 preferred not to say; mean age 34). The average age when participants started to smoke was 16.6 years old. The average number of years of smoking was 16.1 (min 1 - max 45). Respondents smoked on average 16.8 cigarettes per day before quitting.

\section{Data analysis}

To evaluate our model and test our hypotheses we used a three-stage approach. First, as advocated by Hair et al. [45], we evaluated the reliability, validity and significance of our model. Second, we analyzed the overall results, focusing on a macro view of the 
model to test hypotheses $\mathrm{H} 1$ and $\mathrm{H} 2$. Finally, we tested hypotheses $\mathrm{H} 1 \mathrm{a}, \mathrm{H} 1 \mathrm{~b}$ and $\mathrm{H} 3$ with an in-depth path analysis from a micro view of the model. SmartPLS was used as the analysis tool.

\subsection{Evaluation of the model}

To evaluate the reliability of our reflective constructs (i.e. information-seeking, status-seeking, entertainment, providing help and seeking help) we used composite reliability (CR) and average variance extracted (AVE) as indicators. As shown in Table 3, the CR of all the constructs was greater than 0.7 and the AVE greater than 0.5 , hence these constructs are considered reliable [45].

\begin{tabular}{lllll} 
& $\begin{array}{l}\text { Cronbach's } \\
\text { Alpha }\end{array}$ & rho $\boldsymbol{A}$ & $\boldsymbol{C R}$ & AVE \\
\hline Information-seeking & 0.822 & 0.860 & 0.890 & 0.730 \\
Status-seeking & 0.553 & 0.583 & 0.765 & 0.527 \\
Entertainment & 0.646 & 0.711 & 0.793 & 0.568 \\
Providing help & 0.873 & 0.880 & 0.940 & 0.887 \\
Seeking help & 0.711 & 0.712 & 0.874 & 0.776 \\
\hline
\end{tabular}

Table 3. Evaluation of reflective constructs

To evaluate the convergent validity of the reflective construct, we considered outer loadings and the AVE of the indicators [47]. The outer loadings of all our reflective variables were above 0.7 (the standard threshold [47]), except from one indicator in status-seeking and another in entertainment that were above 0.6. As this study is an exploratory research, we decided to keep indicators between 0.4 and 0.7 , as recommended by Hair et al. [47].

To measure the discriminant validity of our reflective constructs, we measured the Heterotrait-Monotrait Ratio (HTMT) [45]. The rule of thumb accepts values lower than 0.85 for conceptually distinct constructs and below 0.90 for conceptually similar constructs. As shown in Table 4, all values were lower than 0.85 , demonstrating the discriminant validity of our constructs.

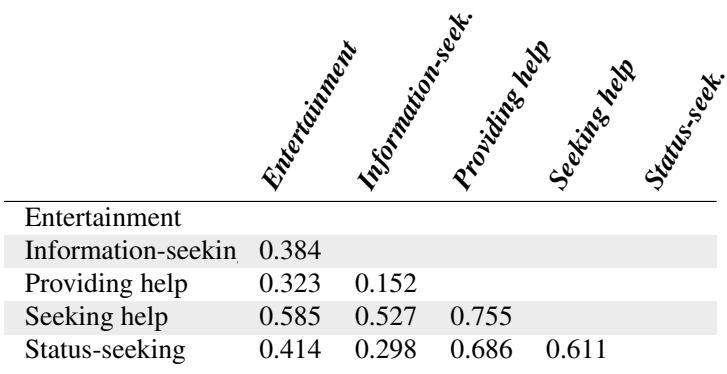

Table 4. Heterotrait-monotrait ratio (HTMT)

To validate our formative constructs, we measured the variance inflation factor (VIF), defined as the reciprocal of the tolerance. The VIFs of our formative

\begin{tabular}{llllll} 
Construct & Indicator & $\begin{array}{l}\text { Outer } \\
\text { Weight }\end{array}$ & t-value & p-value & VIF \\
\hline \multirow{4}{*}{ Motivation } & Information-seeking & 0.259 & 4.812 & 0.000 & 1.284 \\
Participate & Status-seeking & 0.251 & 7.090 & 0.000 & 1.377 \\
& Providing help & 0.340 & 9.452 & 0.000 & 1.783 \\
& Seeking help & 0.328 & 14.609 & 0.000 & 2.129 \\
& Entertainment & 0.245 & 8.598 & 0.000 & 1.343 \\
\hline \multirow{3}{*}{ Active Engagement } & Posting & 0.303 & 1.238 & 0.216 & 1.871 \\
& Commenting & 0.584 & 2.561 & 0.010 & 1.908 \\
& Voting & 0.324 & 1.745 & 0.081 & 1.219 \\
\hline \multirow{2}{*}{ Passive Engagement } & Reading & 0.613 & 2.799 & 0.005 & 1.145 \\
& Visiting & 0.602 & 2.845 & 0.004 & 1.145 \\
\hline \hline \multirow{3}{*}{ Precontemplation } & Consciousness rai. & 0.198 & 1.133 & 0.257 & 1.343 \\
& Dramatic relief & 0.415 & 2.993 & 0.003 & 1.236 \\
& Environmental re. & 0.666 & 5.247 & 0.000 & 1.234 \\
\hline \multirow{3}{*}{ Maintenance } & Counterconditioning & 0.302 & 3.115 & 0.002 & 1.426 \\
& Helping rel. & 0.476 & 4.880 & 0.000 & 1.180 \\
& Reinforcement m. & 0.374 & 3.907 & 0.000 & 1.257 \\
& Stimulus control & 0.253 & 2.321 & 0.020 & 1.303 \\
\hline \hline
\end{tabular}

Table 5. Evaluation of formative constructs

constructs indicating values lower than 5 (Table 5) exclude potential collinearity problems [47].

Weights express a formative indicator's relative importance in forming the construct. Significance indicates whether formative indicators truly contribute to forming the construct. The results presented in Table 5 depict the indicator's weight and significance for each formative construct. All the indicators of the motivation to participate construct were highly significant $(\mathrm{p}<0.001)$. Concerning the engagement indicators, the frequency of posting and voting were not significant $(p>0.05)$ in the determination of individuals' active engagement. In the same way, consciousness raising was not found to be a significant determinant in the users' progression from precontemplation to contemplation stage. As recommended by Hair et al. [47], we verified that for outer loadings of non-significant indicators found in our study, all values were high $(>0.5)$ and indicators were eventually retained, bearing in mind that such indicators had an absolute and not relative importance. To assess the high-level hypotheses (H1 and $\mathrm{H} 2$ ), we extracted latent variable scores of motivation to participate, engagement and process of change constructs.

\section{Results}

Figure 2 shows that the link between engagement and process of change is significant and positive. The more users are engaged in the community, the higher their process of change. H1 is supported.

Figure 2 shows that motivation to participate and engagement are significant and positive. The more motivated users are to participate, the more they actually participate. $\mathrm{H} 2$ is supported.

Looking further into the motivation to participate construct enabled us to further test hypotheses $\mathrm{H} 2$ and 


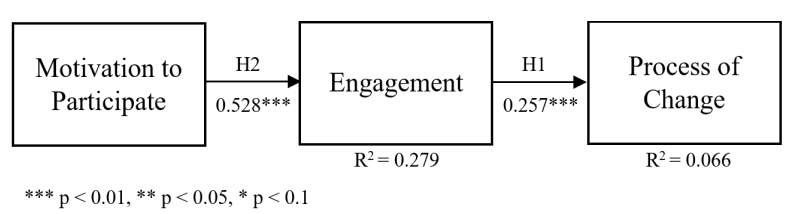

Figure 2. Overall results from macroscopic view of the model

H3. Motivation to participate in $\mathrm{r} /$ StopSmoking was found to be significantly influenced (see Table 5) by all uses and gratification factors: information-seeking, status-seeking, providing help, seeking help and entertainment factors. The most influential motivational factors are: providing help (0.340), followed by seeking help (0.328), information-seeking (0.259), status-seeking (0.251) and entertainment (0.245). Thus, providing help and seeking help are the most influential motivational factors. $\mathrm{H} 3$ is supported.

Path coefficients of our model indicate that the motivation to participate in $\mathrm{r} /$ StopSmoking has a strong effect on the individuals' active engagement (0.496) and on individuals' passive engagement (0.335), both being highly significant $(\mathrm{p}<0.001)$.

Overall influence of the engagement on the process of change, with $6.6 \%$ of the total variance explained. The quite poor influence of $\mathrm{r} /$ StopSmoking overall engagement on the process of change is not surprising as it is difficult to have an influence on every stage of the process at the same time. That's the reason why we tested hypotheses $\mathrm{H} 1 \mathrm{a}$ and $\mathrm{H} 1 \mathrm{~b}$ at a lower level of granularity and analyzed the influence of both active and passive engagement on each stage independently. Both $\mathrm{H} 1 \mathrm{a}$ and $\mathrm{H} 1 \mathrm{~b}$ are supported, with different influences on the stages of change whenever individuals perform active or passive engagement. Active engagement influenced only processes of change moving on maintenance in a strongly significant manner, while passive engagement influenced processes of change moving on precontemplation, contemplation and maintenance with different levels of significance (see Figure 3).

\section{Discussion}

Our findings provide support that the overall engagement in smoking cessation communities is positively correlated to the process of change (H1). This means that the frequency of participation in $\mathrm{r} /$ StopSmoking has an influence on the overall process of change. The results show a significant but modest relation between the overall engagement and the overall process of change. We argue that a lower level of granularity is needed to better perceive the influences of such engagement on each specific stage of the process of change.

This study has shown that active online engagement in smoking cessation communities is positively correlated to the process of change (H1a). This means that users who frequently post, comment and vote will be helped in the achievement of TTM processes, which will take them through the TTM stages of change. Our results show that active engagement is significantly correlated to the maintenance stage, meaning that frequency of commenting, posting and voting helps ex-smokers to not relapse, but it does not help in the previous stages.

Our results show that passive online engagement in smoking cessation communities is positively correlated to the process of change, meaning that the more frequently someone visits and reads content on $\mathrm{r} /$ StopSmoking the more likely they are to progress in their smoking cessation process (H1b). Based on these results, the frequency of reading and visiting potentially predicts precontemplation and maintenance stages. This means that passive engagement can help a smoker to progress from the precontemplation to the contemplation stage, but it can also help to avoid relapsing when in the maintenance stage.

The results also show that uses and gratification motivational factors are positively linked to engagement in online smoking cessation communities (H2). In other words, information-seeking, status-seeking, socialization (providing help and seeking help) and entertainment are all positively contributing to the motivation to participate and consequently to the online engagement of the user. The results show that all the motivational factors positively and significantly influence the overall, active and passive engagement.

Our findings also demonstrate that providing help and seeking help play an important role in the motivation to participate in online smoking cessation communities (H3). Providing help has been found to be the most motivating factor of participation, even more motivating than seeking help, supporting the presence of expert patients who are willing to provide experience and support to newcomers.

\subsection{Academic contributions}

As a contribution to research, our work is a first step into a more nuanced understanding of motivation to participate in digital smoking cessation communities and its behavioral impact on individuals' online engagement and offline smoking cessation process of change. We were able to demonstrate the validity of a model measuring the influence of engagement 


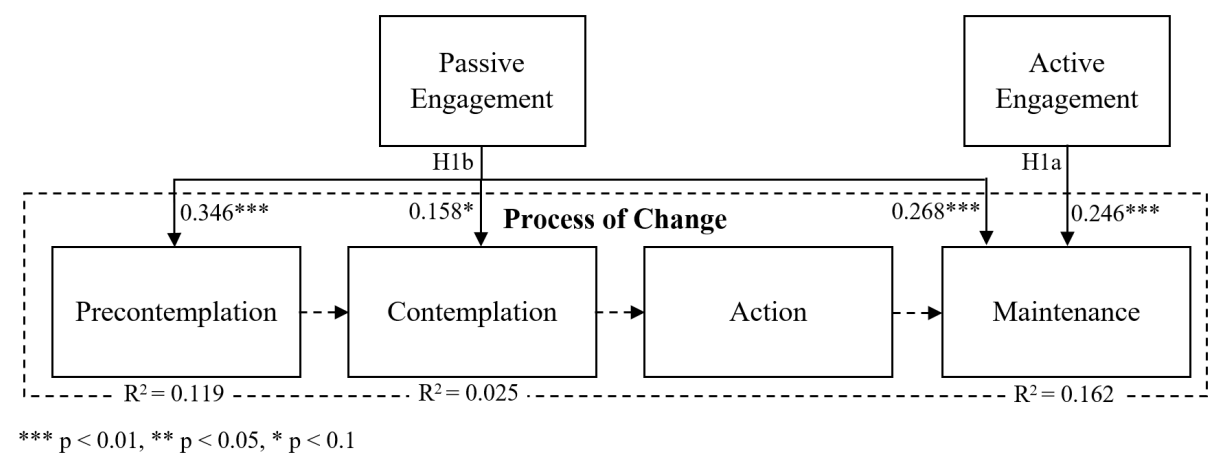

Figure 3. Influence of active and passive engagement on the stages of change

in online smoking cessation communities on offline smoking behavior as well as potential motivational antecedents to such engagement. TTM's stages of change and its mediating processes have been used to measure the progress between the various stages, showing a significant support of online communities in the precontemplation to contemplation transition as well as on the maintenance to termination one.

The uses and gratification approach allowed us to identify motivational factors of such digital communities. This study confirmed status-seeking and entertainment as relevant motivational factors of online engagement, these findings being consistent with previous literature $[33,36]$. This study also found the information-seeking factor to be one of the most salient motivational factors examined, contradicting previous research on Reddit engagement [33], but being aligned with conclusions of other literature relating Facebook online communities [38]. With Reddit containing such a variety of topics and therefore of different communities, we believe that uses and gratification can vary from one community to another. Especially when participating in a subreddit, such as $\mathrm{r} / \mathrm{StopSmoking,} \mathrm{where} \mathrm{the}$ community is driven by a common health-related goal, the uses and gratifications may be different than another random community driven by a completely different goal. This study extended the uses and gratification approach by extending the socialization factor, giving a better understanding of social interaction motivation. This novel definition of the socialization factor, through providing help and seeking help subfactors, found them to be the most significant motivational predictors of the overall motivation to engage in $\mathrm{r} /$ StopSmoking.

\subsection{Implications for practice}

In the various processes mediating the progress between stages of change, we observed that early and late stages of the overall process were significantly supported by online engagement. More specifically, we observed highly significant correlation between passive engagement and the stages of precontemplation and maintenance. This means that visiting and reading online communities could give smokers the intent to stop smoking within the next 6 months or help them to stay smoke free when they are not $100 \%$ confident about being able to do so. High significance correlation between the active engagement and maintenance stages further confirms the effectiveness of online communities in keeping ex-smokers away from temptation and relapses.

Encouraging smokers to share their experience on online smoking cessation communities could help them in their own process of change. It could also help them to potentially become expert patients who will then be even more helped [42]. Interestingly, the three most relevant factors of motivation to engage in digital smoking cessation communities are aligned with primary care interventions of strong efficacy [3]. Providing and seeking help on online communities could be assimilated to peer-group behavioral support, while information-seeking could be assimilated to self-help material. Introducing smokers to these digital smoking cessation communities could trigger motivational factors, which in turn would be effective in the process of behavior change. Further research on a long-term basis is still needed to verify these assertions.

\subsection{Limitations and future research}

This research is not without limitation. A first limitation is related to the sample size $(\mathrm{N}=169)$ and selection process, which might not contain representative members of the community. A second limitation is that the model is only based on survey answers and not on users' activity traces on the subreddit, which could be used to refine the engagement constructs and include temporality. A third limitation is that the model only includes a partial view of the smoking behavior of a user and very limited context 
(e.g. health conditions, demographic context, family context). A fourth limitation is the fact that we did not integrate the preparation stage because there is no clear process allowing people to move from preparation to action. This transition could warrant more attention in future work since it can be particularly challenging.

Future research should investigate the issue through multimodal analytics combining survey results with activity traces over an extended period of time. Furthermore, future work could investigate how to encourage expert patients to become more active online. Visualizing activity traces could be one way to motivate this behavior [48]. Finally, another interesting research topic would be to test if the model can be applied to other addictions or other behavioral problems (e.g. eating disorders).

\section{Conclusion}

In this research paper, we presented a novel model, investigating the influence of digital smoking cessation communities engagement on the actual smokers' behavior in their process of change. We also investigated the motivational factors of such participation in online communities while extending the uses and gratification approach to fit the special context of smoking cessation. To do so, we used survey data from 169 Reddit contributors of the r/StopSmoking thread. The results show that active and passive engagement in online smoking cessation communities has a significant influence on the process of change, mainly in the precontemplation and maintenance stages of the TTM stages of change. We identified that uses and gratification motivational factors are correlated to online smoking cessation communities engagement. The novel structure of the socialization factor, including providing help and seeking help, is relevant because they were found to be the main predictors of the individuals' motivation to engage in such virtual communities. We believe that the results of this research could apply to the withdrawal from addiction in general.

\section{Acknowldgements}

This research was partially funded by the Hasler Foundation and by the Swiss Learning Health System (SLHS) project.

\section{References}

[1] WHO, “Tobacco." https://www.who.int/ news-room/fact-sheets/detail/tobacco, 2020.

[2] WHO, "Global action plan for the prevention and control of noncommunicable diseases 2013-2020,"
World Health Organization, 2013.

[3] M. Verbiest, E. Brakema, R. Van Der Kleij, K. Sheals, G. Allistone, S. Williams, A. McEwen, and N. Chavannes, "National guidelines for smoking cessation in primary care: A literature review and evidence analysis," NPJ Primary Care Respiratory Medicine, pp. 1-11, 2017.

[4] S. Shiffman, S. E. Brockwell, J. L. Pillitteri, and J. G. Gitchell, "Use of smoking-cessation treatments in the United States," American journal of preventive medicine, pp. 102-111, 2008.

[5] J. Hartmann-Boyce, L. F. Stead, K. Cahill, and T. Lancaster, "Efficacy of interventions to combat tobacco addiction: Cochrane update of 2013 reviews," Addiction, pp. 1414-1425, 2014.

[6] J. Paay, J. Kjeldskov, U. Brinthaparan, L. Lichon, S. Rasmussen, N. Srikandaraja, W. Smith, G. Wadley, and B. Ploderer, "Quitty: using technology to persuade smokers to quit," in Proceedings of the 8th Nordic Conference on Human-Computer Interaction: Fun, Fast, Foundational, pp. 551-560, 2014.

[7] R. West, M. Raw, A. McNeill, L. Stead, P. Aveyard, J. Bitton, J. Stapleton, H. McRobbie, S. Pokhrel, A. Lester-George, and R. Borland, "Health-care interventions to promote and assist tobacco cessation: A review of efficacy, effectiveness and affordability for use in national guideline development," Addiction, pp. 1388-1403, 2015.

[8] A. De Santo and A. Holzer, "Assessing digital support for smoking cessation," in European, Mediterranean, and Middle Eastern Conference on Information Systems, pp. 331-343, 2019.

[9] Y. Lin, C. Tudor-Sfetea, S. Siddiqui, Y. Sherwani, M. Ahmed, and A. B. Eisingerich, "Effective behavioral changes through a digital mHealth app: Exploring the impact of hedonic well-being, psychological empowerment and inspiration," Journal of Medical Internet Research, p. e10024, 2018.

[10] L. Sardi, A. Idri, and J. L. Fernández-Alemán, “A systematic review of gamification in e-Health," Journal of Biomedical Informatics, pp. 31-48, 2017.

[11] N. A. Christakis, "Health care in a web," $B M J$, pp. 1468-1468, 2008.

[12] J. L. Westmaas, J. Bontemps-Jones, and J. E. Bauer, "Social support in smoking cessation: reconciling theory and evidence," Nicotine \& Tobacco Research, pp. 695-707, 2010.

[13] S. Cohen and E. P. Lemay, "Why would social networks be linked to affect and health practices?" Health Psychology, pp. 410-417, 2007.

[14] R. S. Sadasivam, R. L. Kinney, S. C. Lemon, S. L. Shimada, J. J. Allison, and T. K. Houston, "Internet health information seeking is a team sport: analysis of the Pew Internet Survey," International journal of medical informatics, pp. 193-200, 2013.

[15] S. L. Cutrona, D. W. Roblin, J. L. Wagner, B. Gaglio, A. E. Williams, R. T. Stone, T. S. Field, and K. M. Mazor, "Adult willingness to use email and social media for peer-to-peer cancer screening communication: quantitative interview study," JMIR research protocols, p. e52, 2013.

[16] A. Tamersoy, D. H. Chau, and M. De Choudhury, "Analysis of smoking and drinking relapse in an online community," in Proceedings of the 2017 International Conference on Digital Health, pp. 33-42, 2017. 
[17] N. K. Cobb, M. A. Jacobs, J. Saul, E. P. Wileyto, and A. L. Graham, "Diffusion of an evidence-based smoking cessation intervention through Facebook: a randomised controlled trial study protocol," BMJ open, p. e004089, 2014.

[18] J. O. Prochaska, C. C. DiClemente, and J. C. Norcross, "In search of how people change: Applications to addictive behaviors," Addictions Nursing Network, pp. 2-16, 1993.

[19] R. Schwarzer and A. Luszczynska, "How to overcome health-compromising behaviors: The health action process approach,” European Psychologist, pp. 141-151, 2008.

[20] J. O. Prochaska, C. A. Redding, K. E. Evers, et al., "The transtheoretical model and stages of change," Health behavior: Theory, research, and practice, pp. 125-148, 2015.

[21] R. West, "Time for a change: putting the transtheoretical (stages of change) model to rest," Addiction, pp. 1036-1039, 2005.

[22] T. A. Herzog and C. O. Blagg, "Are most precontemplators contemplating smoking cessation? Assessing the validity of the stages of change," Health Psychology, vol. 26, no. 2, p. 222, 2007.

[23] J. O. Prochaska, C. A. Redding, K. E. Evers, et al., "The transtheoretical model and stages of change," Health behavior: Theory, research, and practice, pp. 97-122, 2015.

[24] N. J. Roberts, S. M. Kerr, and S. M. Smith, "Behavioral interventions associated with smoking cessation in the treatment of tobacco use," Health Services Insights, pp. 79-85, 2013.

[25] C. A. Maher, L. K. Lewis, K. Ferrar, S. Marshall, I. De Bourdeaudhuij, and C. Vandelanotte, "Are health behavior change interventions that use online social networks effective? a systematic review," Journal of medical Internet research, p. e40, 2014.

[26] A. L. Graham, G. D. Papandonatos, and K. Zhao, "The failure to increase social support: it just might be time to stop intervening (and start rigorously observing)," Translational Behavioral Medicine, pp. 816-820, 2017.

[27] S. Ziebland and S. Wyke, "Health and illness in a connected world: how might sharing experiences on the internet affect people's health?," The Milbank Quarterly, pp. 219-249, 2012.

[28] N. K. Cobb, A. L. Graham, M. J. Byron, D. B. Abrams, et al., "Online social networks and smoking cessation: a scientific research agenda," Journal of medical Internet research, p. e119, 2011.

[29] M. J. Dutta-Bergman, "Primary sources of health information: Comparisons in the domain of health attitudes, health cognitions, and health behaviors," Health communication, pp. 273-288, 2004.

[30] G.-Y. Noh, S. Y. Lee, and J. Choi, "Exploring factors influencing smokers' information seeking for smoking cessation," Journal of health communication, pp. 845-854, 2016.

[31] L. Stead, A. Carroll, and T. Lancaster, "Group behaviour therapy programmes for smoking cessation ( Review )," Cochrane Database of Systematic Reviews Group, 2017.

[32] N. Grinberg, P. A. Dow, L. A. Adamic, and M. Naaman, "Changes in engagement before and after posting to facebook," in Proceedings of the 2016 CHI Conference on Human Factors in Computing Systems, pp. 564-574, 2016.
[33] C. Moore and L. Chuang, "Redditors revealed: Motivational factors of the reddit community," in Proceedings of the 50th Hawaii International Conference on System Sciences, 2017.

[34] C. S. Lee, L. Ma, and D. H. L. Goh, "Why do people share news in social media?," Lecture Notes in Computer Science (including subseries Lecture Notes in Artificial Intelligence and Lecture Notes in Bioinformatics), pp. 129-140, 2011.

[35] J. G. Blumler and E. Katz, "The uses of mass communications: Current perspectives on gratifications research," Sage Annual Reviews of Communication Research, 1974.

[36] N. Park, K. F. Kee, and S. Valenzuela, "Being immersed in social networking environment: Facebook groups, uses and gratifications, and social outcomes," Cyberpsychology and Behavior, pp. 729-733, 2009.

[37] Z. Papacharissi and A. M. Rubin, "Predictors of internet use," Journal of broadcasting \& electronic media, pp. 175-196, 2000.

[38] S. Rafaeli, T. Hayat, and Y. Ariel, "Virtual knowledge-building communities," in Encyclopedia of Networked and Virtual Organizations, pp. 1792-1796, IGI Global, 2008.

[39] A. Diddi and R. LaRose, "Getting hooked on news: Uses and gratifications and the formation of news habits among college students in an internet environment," Journal of Broadcasting \& Electronic Media, pp. 193-210, 2006.

[40] B. Ploderer, W. Smith, J. Pearce, and R. Borland, "A mobile app offering distractions and tips to cope with cigarette craving: a qualitative study," JMIR mHealth and uHealth, p. e23, 2014.

[41] L. Eskreis-Winkler, A. Fishbach, and A. L. Duckworth, "Dear Abby: Should I Give Advice or Receive It?" Psychological Science, pp. 1797-1806, 2018.

[42] L. Eskreis-Winkler, K. L. Milkman, D. M. Gromet, and A. L. Duckworth, "A large-scale field experiment shows giving advice improves academic outcomes for the advisor," Proceedings of the National Academy of Sciences of the United States of America, pp. 14808-14810, 2019.

[43] K. K.-K. Wong, "Partial least squares structural equation modeling (pls-sem) techniques using smartpls," Marketing Bulletin, vol. 24, no. 1, pp. 1-32, 2013.

[44] M. Sarstedt, C. M. Ringle, and J. F. Hair, "Partial least squares structural equation modeling," Handbook of market research, pp. 1-40, 2017.

[45] J. Hair, C. L. Hollingsworth, A. B. Randolph, and A. Y. L. Chong, "An updated and expanded assessment of PLS-SEM in information systems research," Industrial Management and Data Systems, pp. 442-458, 2017.

[46] K. A. Bollen, "Latent variables in psychology and the social sciences," Annual review of psychology, pp. 605-634, 2002.

[47] J. F. Hair Jr, G. T. M. Hult, C. Ringle, and M. Sarstedt, A primer on partial least squares structural equation modeling (PLS-SEM). Sage publications, 2016.

[48] A. Holzer, B. Kocher, S. Bendahan, I. Vonèche Cardia, J. Mazuze, and D. Gillet, "Gamifying knowledge sharing in humanitarian organisations: a design science journey," European Journal of Information Systems, pp. 153-171, 2020. 